\title{
Validation of HPLC Method for Quantitative Determination of Pirimiphos methyl
}

\author{
C. Tamilselvan*, S. John Joseph, G. Mugunthan, S. Syed Musthaq Ahamed \\ Bioscience Research Foundation, Porur, Chennai 600 116, Tamil Nadu, India \\ *E-mail address: brfchennai@gmail.com
}

\begin{abstract}
The objective of this research to optimise the HPLC method was developed for quantitative determination of Pirimiphos-methyl. Chromatographic separation was achieved on a $250 \mathrm{x} 4.6 \mathrm{~mm}$ i.d. reversed phase column Qualisil BDS $5 \mathrm{u}$ C18, Using deionized acetonitrile:water in the ratio of $85: 15 \mathrm{v} / \mathrm{v}$ respectively as mobile phase. The eluent was monitored at $254 \mathrm{~nm}$. A sharp peak was obtained for the Pirimiphos-methyl at $9.29 \mathrm{~min}$. The UV Spectrophotometric method performed at $254 \mathrm{~nm}$ after full scan analysis using methanol as a solvent. The result revealed that both methods are suitable to carry out routine analysis of Pirimiphos methyl, However HPLC results showed high precise, accurate and sensitive than the UV Spectrophotometer. Hence HPLC method is suitable for trace analysis of Pirimiphos methyl in environmental samples.
\end{abstract}

Keywords: Pirimiphos methyl; HPLC; UV-spectrophotometric; Linearity; Precision; Recovery; Quantification; LOD and LOQ

\section{INTRODUCTION}

Pirimiphos methyl [O-2-(diethylamino)-6-methylpyrimidin-4-yl O,O-dimethyl phosphorothioate] is an phosphorothioate, which is a broad-spectrum insecticide and acaricide with contact and respiratory action. It shows activity against a wide variety of insects including ants, aphids, beetles, caterpillars, cockroaches, fleas, flies, mites, mosquitoes, moths, and thrips. It penetrates the leaf tissue and exhibits translaminar action. It control of a wide range of insects and mites in warehouses, stored grain, animal houses, domestic and industrial premises. Pirimiphos methyl is rapidly absorbed, metabolized and excreted in rats and dogs. In both species, 2-ethyl amino-4-hydroxy-6-methyl pyrimidine is the major metabolite [1]. The reproductive organs have been shown to be among the most vulnerable organs to organophosphorous insecticides [2-4].

Pirimiphos-methyl is a cheap pesticide widely used in the world and particularly in Africa to protect food against pests. Pirimiphos-methyl is a fast-acting broad spectrum insecticide with both contact and fumigant action. Pirimiphos-methyl has a half-life [5] of 117 days in water (Yamada 2005; Bullock 1974), 180-270 days on greens and seeds, and 130 days in soil (Bowker et al. 1972). The chemical name of pirimiphos methyl [6] is $O$-(2diethylamino-6-methylpyrimidin-4-yl)- $O, O$-dimethyl phosphorothioate. Its structural formula can be seen in Figure 1. 


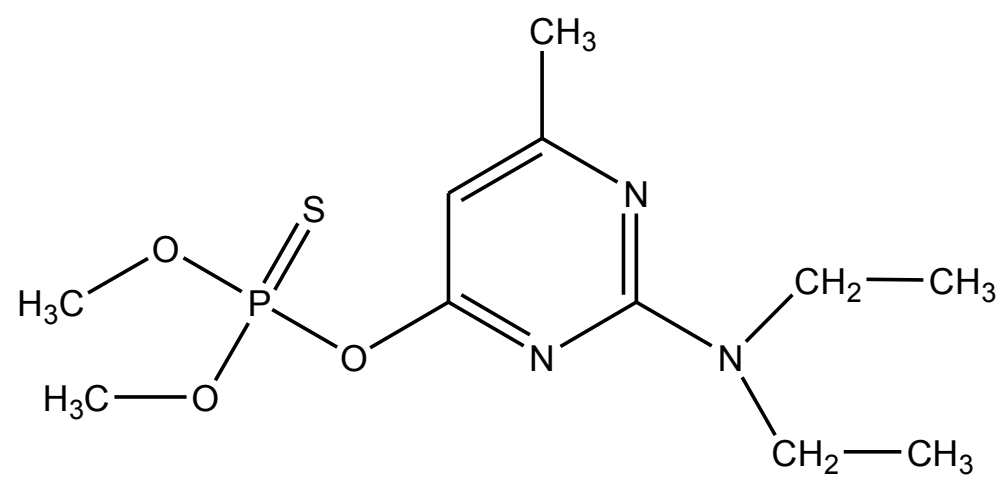

Figure 1. Chemical structural of pirimiphos methyl.

Different chromatographic methods followed for the determination of Pirimiphos methyl in food and environmental samples [7-8]. For example, limits of detection (LOD) between 0.05 and $0.5 \mathrm{ng} / \mathrm{ml}$ were reached using thin layer chromatography (TLC) [9]; also high performance liquid chromatography (HPLC) with LOD of $16 \mathrm{ng} / \mathrm{ml}$ for the analysis of Pirimiphos methyl in water [10-11]. In addition, gas chromatography (GC) coupled to nitrogen/phosphorous (NPD) [12-13], atomic emission (AED) [14], electron capture (ECD) [15] or flame photometric detectors (FPD) [16] have also been applied for the determination of Pirimiphos methyl. The aim of this paper is to develop and validate HPLC and UV visible method using a suitable conditions method for the determination of Pirimiphos methyl.

\section{MATERIALS AND METHODS}

Solvents (acetonitrile, methanol and reference standard Pirimiphos methyl) and HPLC water used for this study were sigma aldrich and merck respectively.

\section{1. Instrumentation and analytical conditions}

HPLC analyses were performed using the LC-10AT VP and SPD-10A UV-VIS Detector of Shimadzu with PC integrator. A reversed-phase column (Qualisil BDS 5u C18, Size-250 x $4.6 \mathrm{~mm}$ (i.d); particle size $5 \mu \mathrm{m}$ ). The room temperature maintained at $32{ }^{\circ} \mathrm{C}$. The mobile phase was a mixture of acetonitrile /water $(85 / 15, \mathrm{v} / \mathrm{v})$ with a flow rate of $1.0 \mathrm{~mL} / \mathrm{min}$. the detection was at $254 \mathrm{~nm}$ when the injection volume was $20 \mu \mathrm{L}$.

The UV spectrophotometric method was performed using shimadzu UV-Visible double beam spectrophotometer model 1700 pharma spec. UV-Visible is controlled by PC and UV probe personal software package. The analysis was performed with methanol as a solvent.

\section{2. Linearity}

\section{Preparation of Stock solution:}

Accurately weighed $137.0 \mathrm{mg}$ of Pirimiphos-methyl standard (99.50\% purity) in 100 $\mathrm{ml}$ standard flask, added sufficient volume of mobile phase to dissolve the contents and make up the volume up to the mark of standard flask. 


\section{Preparation of calibration solutions:}

From the above stock solution, made serial dilution for further preparation of concentrations such as 9.59, 10.96, 12.33, 13.70, 15.07 and $16.44 \mathrm{mg}$ in $100 \mathrm{ml}$ standard flasks separately. The standard solutions were allowed to stand for 30 minutes at room temperature for equilibration.

Injected each standard in the HPLC system thrice and recorded the corresponding peak areas were presented in Table 1 and calibration chart were presented in Figure 2.

\section{Table 1}

\begin{tabular}{|c|c|c|}
\hline $\begin{array}{c}\text { Weight } \\
\text { (mg) }\end{array}$ & $\begin{array}{c}\text { Area } \\
(\mathrm{mV} \cdot \mathrm{Sec})\end{array}$ & $\begin{array}{c}\text { Mean Area } \pm \text { SD } \\
(\mathrm{mV} \cdot \mathrm{Sec})\end{array}$ \\
\hline \multirow{3}{*}{9.59} & 9182.6374 & \multirow{3}{*}{$\begin{array}{c}9182.5869 \\
\pm 0.4943\end{array}$} \\
\hline & 9183.0541 & \\
\hline & 9182.0693 & \\
\hline \multirow{3}{*}{10.96} & 10642.3293 & \multirow{3}{*}{$\begin{array}{c}10643.2536 \\
\pm 1.3040\end{array}$} \\
\hline & 10644.7452 & \\
\hline & 10642.6863 & \\
\hline \multirow{3}{*}{12.33} & 11981.0531 & \multirow{3}{*}{$\begin{array}{c}11980.3312 \\
\pm 0.9501\end{array}$} \\
\hline & 11979.2549 & \\
\hline & 11980.6857 & \\
\hline \multirow{3}{*}{13.70} & 13306.9827 & \multirow{3}{*}{$\begin{array}{c}13306.9894 \\
\pm 0.3342\end{array}$} \\
\hline & 13307.3269 & \\
\hline & 13306.6587 & \\
\hline \multirow{3}{*}{15.07} & 14638.3305 & \multirow{3}{*}{$\begin{array}{c}14637.9342 \\
\pm 0.9272\end{array}$} \\
\hline & 14638.5974 & \\
\hline & 14636.8748 & \\
\hline \multirow{3}{*}{16.44} & 16329.3297 & \multirow{3}{*}{$\begin{array}{c}16330.3468 \\
\pm 1.4200\end{array}$} \\
\hline & 16331.9692 & \\
\hline & 16329.7416 & \\
\hline
\end{tabular}




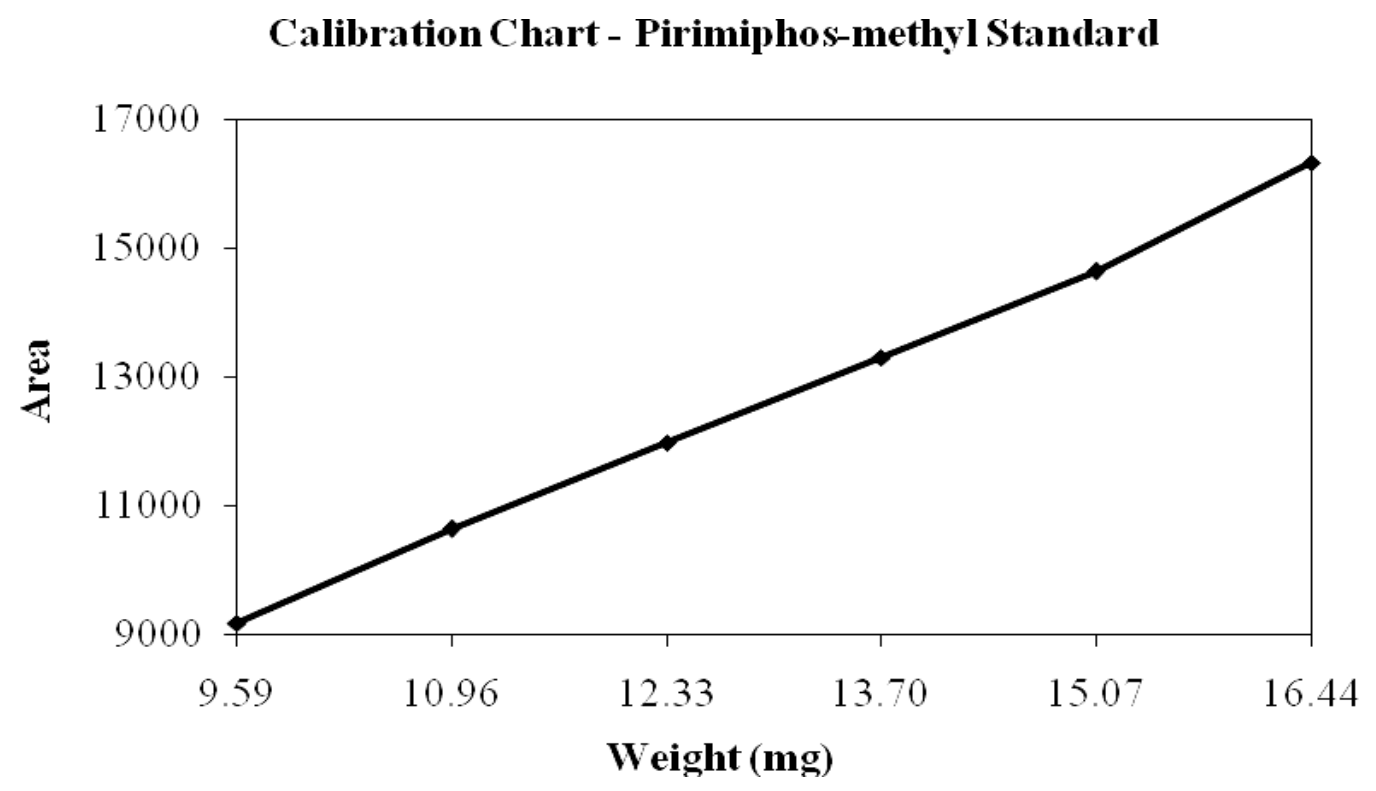

Figure 2. Calibration chart of Pirimiphos-methyl.

Statistical Parameters

\begin{tabular}{|c|c|}
\hline Slope & 1.0482 \\
\hline Correlation & 0.9992 \\
\hline Intercept & 2.9346 \\
\hline
\end{tabular}

\section{3. Precision}

\section{Preparation of Standard Solution:}

Use the concentration of $4^{\text {th }}$ Linearity standard $(13.70 \mathrm{mg} / 100 \mathrm{ml})$ or Pipette out $10 \mathrm{ml}$ of stock solution into $100 \mathrm{ml}$ standard flask, added sufficient volume of mobile phase up to the mark of standard flask. The solution was allowed to stand for 30 minutes in room temperature for equilibration.

\section{Preparation of Sample solution:}

Accurately weighed $14.10 \mathrm{mg}$ of Pirimiphos-methyl technical sample in separate 100 $\mathrm{ml}$ standard flask, added sufficient volume of mobile phase to dissolve the content and make up to the mark of standard flask. The solution was allowed to stand for 30 minutes in room temperature for equilibration.

The standard and sample solutions were injected in the HPLC system continuously and recorded the respective peak areas were presented in Table 2. The Pirimiphos-methyl content was calculated using the following formula-1, 


$$
\text { Pirimiphos-methyl content }(\%)=\begin{aligned}
& \mathrm{A} \times \mathrm{B} \\
& -----\mathrm{P} P \longrightarrow 1 \\
& \mathrm{C} \times \mathrm{D}
\end{aligned}
$$

where,
A - Area of Pirimiphos-methyl peak in sample
B - Weight of standard
C - Area of Pirimiphos-methyl peak in standard
D - Weight of sample
P - Purity of reference standard

Table 2

\begin{tabular}{|c|c|c|c|}
\hline Sample & $\begin{array}{c}\text { Weight } \\
(\mathbf{m g})\end{array}$ & $\begin{array}{c}\text { Area } \\
(\mathbf{m V} \cdot \mathbf{S e c})\end{array}$ & $\begin{array}{c}\text { Pirimiphos-methyl } \\
\text { content (\%) }\end{array}$ \\
\hline \multirow{2}{*}{ Standard } & 13.70 & 13306.9827 & - \\
\hline \multirow{3}{*}{ Sample } & \multirow{3}{*}{14.10} & 12996.0369 & 94.418 \\
\cline { 3 - 4 } & & 13001.2574 & 94.456 \\
\cline { 3 - 4 } & & 12991.3941 & 94.385 \\
\cline { 3 - 4 } & & 12998.6024 & 94.437 \\
\cline { 3 - 4 } & & 13003.2319 & 94.471 \\
\hline
\end{tabular}

\begin{tabular}{ccc}
\multicolumn{3}{c}{ Statistical Parameters } \\
Mean & - & \\
Standard Deviation & - & 0.433 \\
Relative Standard Deviation & - & 0.036
\end{tabular}

\section{4. Recovery}

\section{Preparation of Standard Solution:}

Use the concentration of $4^{\text {th }}$ Linearity standard $(13.70 \mathrm{mg} / 100 \mathrm{ml})$ or Pipette out $10 \mathrm{ml}$ of stock solution into $100 \mathrm{ml}$ standard flask, added sufficient volume of mobile phase up to the mark of standard flask. The solution was allowed to stand for 30 minutes in room temperature for equilibration.

\section{Preparation of Blank Sample solution:}

Accurately weighed $14.0 \mathrm{mg}$ of Pirimiphos-methyl technical sample in separate $100 \mathrm{ml}$ standard flasks, added sufficient volume of mobile phase to dissolve the contents and make up to the mark of standard flask. The solution was allowed to stand for 30 minutes in room temperature for equilibration. 


\section{Preparation of fortified standard solutions:}

Pirimiphos-methyl technical sample of $14.0 \mathrm{mg}$ were taken in to three separate $100 \mathrm{ml}$ standard flasks and added sufficient volume of mobile phase to dissolve the contents. To this fortified three levels of standards $0.96,1.92 \& 2.88 \mathrm{mg}$ respectively. Made the standard flasks up to the mark-using Mobile phase and mixed well.

The standard and sample solutions were injected in the HPLC system continuously and recorded the respective peak areas were presented in Table 3. Then calculate the recovery using the following formula,

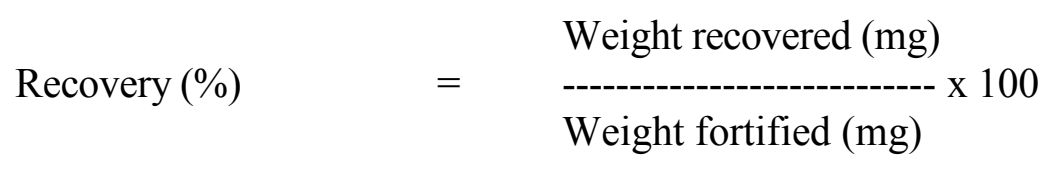

\section{Calculation:}

Standard weight $(\mathrm{mg})$

Area of standard $(\mathrm{mV} \cdot \mathrm{Sec})$

Area of blank sample $(\mathrm{mV} \cdot \mathrm{Sec})$ $=\quad 13.70$

$=\quad 13306.9827$

$=\quad 12955.3297$

Table 3

\begin{tabular}{|c|c|c|}
\hline $\begin{array}{c}\text { Fortified Standard } \\
\text { level (mg) }\end{array}$ & $\begin{array}{c}\text { Fortified Sample Area } \\
(\mathbf{m V} \cdot \mathbf{S e c})\end{array}$ & Recovery (\%) \\
\hline \multirow{2}{*}{0.96} & 13876.6594 & 98.81 \\
\cline { 2 - 3 } & 13872.9990 & 98.41 \\
\hline \multirow{2}{*}{1.92} & 14790.3845 & 98.40 \\
\cline { 2 - 3 } & 14792.4844 & 98.51 \\
\hline \multirow{2}{*}{2.88} & 15714.7282 & 98.64 \\
\cline { 2 - 3 } & 15720.1822 & 98.84 \\
\hline
\end{tabular}

\section{Statistical Parameters}

Mean $\quad$ - $\quad 98.60$

$\begin{array}{lll}\text { Standard Deviation } \quad ~ & 0.194\end{array}$

Relative Standard Deviation $\quad$ - $\quad 0.196$ 


\section{5. Quantification}

\section{Preparation of Standard Solution:}

Use the concentration of $4^{\text {th }}$ Linearity standard $(13.70 \mathrm{mg} / 100 \mathrm{ml})$ or Pipette out $10 \mathrm{ml}$ of stock solution into $100 \mathrm{ml}$ standard flask, added sufficient volume of mobile phase up to the mark of standard flask. The solution was allowed to stand for 30 minutes in room temperature for equilibration.

\section{Preparation of Sample solution:}

Weighed exactly known weight of Pirimiphos-methyl Technical sample in a $100 \mathrm{ml}$ standard flask, added sufficient volume of mobile phase to dissolve the contents and make up to the mark of standard flask. The solution was allowed to stand for 30 minutes in room temperature for equilibration.

The standard \& sample solutions were injected into the HPLC system. From the peak area of consecutive injection of standard solution and sample solution were presented in Table 4. The Pirimiphos-methyl content calculated as per formula-1.

Table 4

\begin{tabular}{|c|c|c|c|c|c|c|}
\hline $\begin{array}{c}\text { Sample } \\
\text { weight } \\
\text { (mg) }\end{array}$ & $\begin{array}{c}\text { Sample } \\
\text { Peak Area } \\
(\mathrm{mV} \cdot \mathrm{Sec})\end{array}$ & $\begin{array}{c}\text { Mean } \\
(\mathrm{mV} \cdot \mathrm{Sec})\end{array}$ & $\begin{array}{c}\text { Standard } \\
\text { weight } \\
\text { (mg) }\end{array}$ & $\begin{array}{c}\text { Standard } \\
\text { Peak Area } \\
(\mathrm{mV} \cdot \text { Sec })\end{array}$ & $\begin{array}{c}\text { Mean } \\
(\mathrm{mV} \cdot \mathrm{Sec})\end{array}$ & $\begin{array}{c}\text { Content } \\
(\%)\end{array}$ \\
\hline \multirow{3}{*}{14.24} & 13116.0561 & \multirow{3}{*}{13116.1175} & \multirow{6}{*}{13.70} & \multirow{2}{*}{13309.2591} & & \multirow{3}{*}{94.337} \\
\hline & 13115.8419 & & & & & \\
\hline & 13116.4544 & & & & & \\
\hline \multirow{3}{*}{14.01} & 12893.3147 & \multirow{3}{*}{12893.5114} & & & & \multirow{3}{*}{94.259} \\
\hline & 12892.8526 & & & \multirow{2}{*}{13309.5847} & & \\
\hline & 12894.3669 & & & & & \\
\hline
\end{tabular}

\section{6. LOD and LOQ}

\section{Limit of Detection \& Limit of Quantification:}

The LOD \& LOQ are determined by analyzing with known diluted standard of Pirimiphos-methyl of different concentrations. From the response of the analyte concentration the signal noise ratio $(\mathrm{S} / \mathrm{N})$ was also calculated for LOD \& LOQ determination were presented in Table 5. 
LOD \& LOQ of primiphos-methyl al content

Table 5

\begin{tabular}{|c|c|c|c|c|c|c|}
\hline $\begin{array}{l}\text { Conc. } \\
\text { (ppm) }\end{array}$ & $\begin{array}{c}\text { Response } \\
\text { (Peak } \\
\text { area) }\end{array}$ & $\begin{array}{c}\text { Mean } \\
\text { Response } \\
\text { (Peak } \\
\text { area) }\end{array}$ & $\begin{array}{c}\text { Mean } \\
\text { Noise } \\
\text { Area for } \\
\text { Blank }\end{array}$ & $\begin{array}{c}\text { Signal to } \\
\text { Noise } \\
\text { Ratio }\end{array}$ & Remark & $\begin{array}{c}\% \text { of } \\
\text { LOD \& } \\
\text { LOQ }\end{array}$ \\
\hline \multirow{2}{*}{0.01} & 0.9689 & \multirow{2}{*}{0.9802} & \multirow{6}{*}{0.3248} & \multirow{2}{*}{3.02} & \multirow{2}{*}{ LOD } & \multirow{2}{*}{0.000001} \\
\hline & 0.9915 & & & & & \\
\hline \multirow[b]{2}{*}{0.02} & 1.8493 & \multirow{2}{*}{1.8879} & & \multirow{2}{*}{5.81} & \multirow[b]{2}{*}{ LOQ } & \multirow[b]{2}{*}{0.000002} \\
\hline & 1.9264 & & & & & \\
\hline \multirow{2}{*}{0.04} & 3.9849 & \multirow{2}{*}{3.9392} & & \multirow{2}{*}{12.13} & \multirow[b]{2}{*}{ - } & \multirow[b]{2}{*}{-} \\
\hline & 3.8934 & & & & & \\
\hline
\end{tabular}

Note: $\mathrm{LOD}=$ signal to noise ratio $3 \pm 0.5 ; \mathrm{LOQ}=$ signal noise ratio between 5 to 10

\section{RESULTS AND DISCUSSION}

\section{1. HPLC Method}

A typical sharp, single peak of pirimiphos methyl chromatogram obtained at $9.29 \mathrm{~min}$ after injection with set off parameters adopted in this study. Figure 3 shows the ideal chromatogram of Pirimiphos-methyl.

The developed method was validated in terms of linearity, precision, recovery, quantification, LOD and LOQ. The standard calibration curve showed in Fig. 2 was linear over the concentration range 9.59 to $16.44 \mathrm{mg}$ with a correlation coefficient $\left(\mathrm{r}^{2}\right) 0.9992$. LOD and LOQ were found to be 0.000001 and $0.000002 \%$ respectively, indicating the sensitivity of the method. Experiments demonstrated satisfactory accuracy with small relative standard deviations 0.36 (RSD \%). The developed HPLC method was precise since the \% RSD values were $0.1<$ for both repeatability and intermediate precision studies. RSD of repeatability (intra-day) and intermediate precision (inter-day) ranged from 0.0241 to 0.03608 and 0.0423 to 0.0662 respectively. Chromatographic conditions were carefully optimized to get satisfactory resolution of the test substance.

The final decision on mobile phase composition and flow rate was made on the basis of peak shape (peak area, asymmetry, tailing factor), baseline drift, time required for analysis, and cost of solvents. The optimized mobile phase was a mixture of acetonitrile/water/ $(85 / 15$, $\mathrm{v} / \mathrm{v}$ ) with a flow rate of $1.0 \mathrm{~mL} / \mathrm{min}$. the detection was made at $254 \mathrm{~nm}$ by making preliminary experiment on the Pirimiphos methyl with using mobile phase compostion as solvent on UV-Visible spectrophotometric showed that there was peak at $254 \mathrm{~nm}$ by applying the wavelength of the HPLC method showed good response with it affected on the LOD to be $0.000001 \%$ and LOQ to be $0.000002 \%$ ppm. 


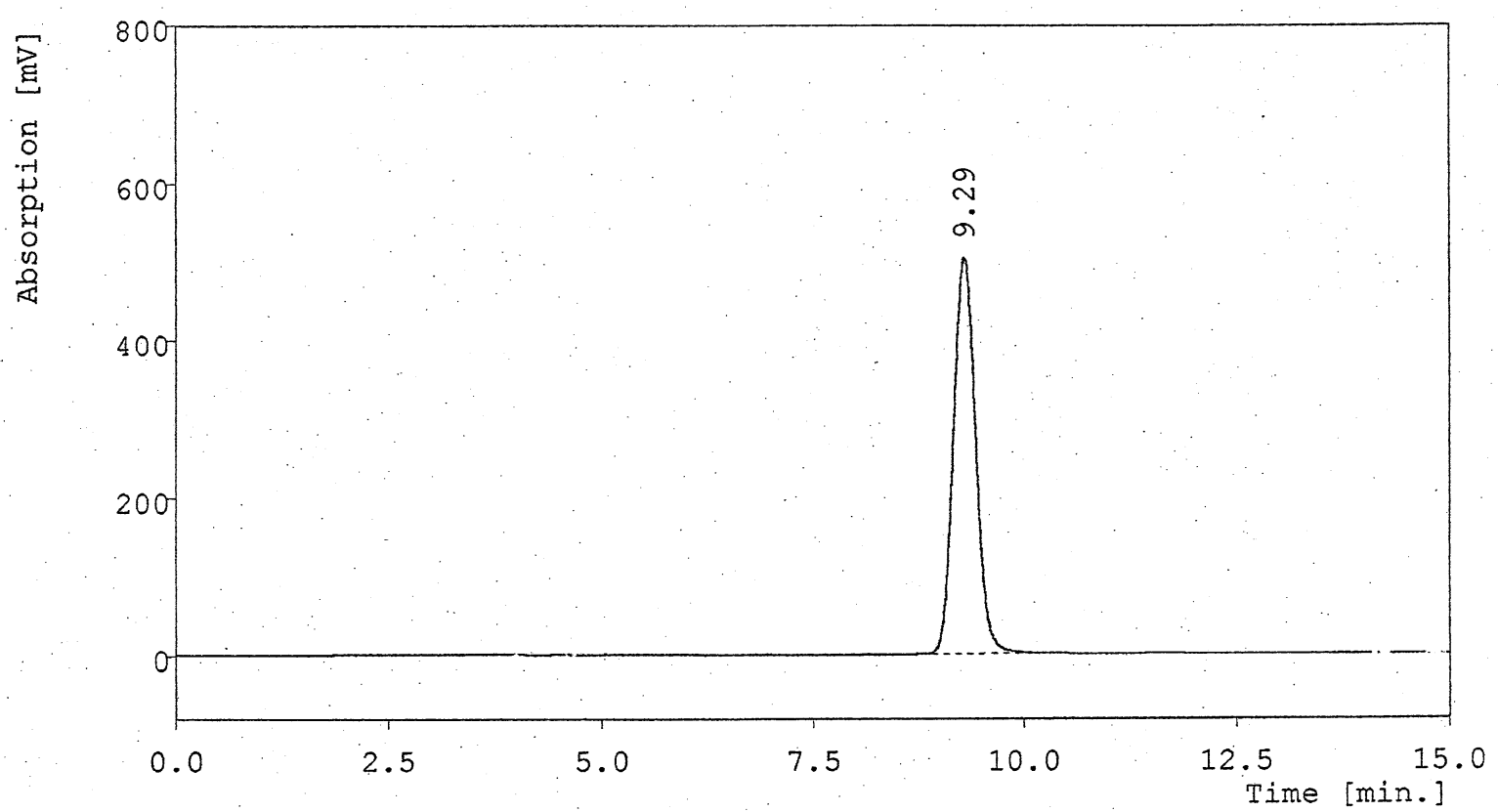

\begin{tabular}{|c|l|r|r|r|l|}
\hline $\begin{array}{c}\text { Peak } \\
\#\end{array}$ & $\begin{array}{c}\text { Ret. } \\
\text { Time }\end{array}$ & Area & Height & Area \% & Name \\
\hline 1 & 9.29 & 9182.6374 & 503.4921 & 100.0000 & Pirimiphos-methyl \\
\hline & & 9182.6374 & 503.4921 & 100.0000 & \\
\hline
\end{tabular}

Figure 3. A typical chromatogram of Pirimiphos methyl.

\section{2. UV-Visible Spectrophotometric method}

The test substance solutions were scanned in the wavelength range 200-1100 nm after making suitable dilutions from the stock solutions. Pirimiphos-methyl showed absorption maxima at 254 and a weaker band at $300 \mathrm{~nm}$. Pirimiph + os-methyl in methanol as a solvent showed linear relationship in the concentration range of 1.246 to $10 \mathrm{mg}$ with a correlation coefficient $\left(\mathrm{r}^{2}\right)$ 0.9991. LOD and LOQ were found to be 1.682 and $5.1 \mathrm{mg}$ respectively. The percentage of RSD value for intra-day and inter-day precision varied from 0.0453 to 0.062 and 0.0542 to 0.9255 respectively. The spectrophotometric method allowed rapid quantification of Pirimiphos-methyl. Methanol was chosen as the solvent because of good solubility.

The use of UV-visible spectroscopy as a primary method of determination in organo phosphorous pesticide quantification experiment has declined to an insignificant level in recent years. This method is based upon the measurement of the absorbency of organo phosphorous spectrophotometric reagent which is sensitive to low microgram amounts. The direct utility of a UV-visible spectroscopic method in pesticides analysis is limited because of its relatively low sensitivity and selectivity. Pirimiphos-methyl showed absorption maxima at $254 \mathrm{~nm}$ which was selected as the detection wavelength since it showed better linearity and sensitivity at this wavelength. 


\section{CONCLUSIONS}

The validated HPLC and UV-Visible methods were found to be accurate, precise and reliable. UV spectrophotometric and HPLC methods are quite simpler. However instrument HPLC is not available UV spectrophotometric method can follow for routine quantification purpose. The test substance Pirimiphos-methyl quantification is very simple and rapid analysis can be performed using HPLC method without any difficulties. The validation results (linear, precise, recovery, quantification, LOD and LOQ) are confirmed the high accuracy of the method.

\section{References}

[1] IE. Mills, Pirimiphos-methyl: blood concentrations and tissue retention in rat. Report No CTL/P/247. Imperial Chemical industries, Central toxicology laboratory, (1976)11.

[2] C. Cox, Journal of Pesticide Reform 2 (1996) 2.

[3] C. Sobarzo, E. Bustoos-Obregón, Asian Journal of Andrology 2 (2000) 147.

[4] E.ustos-Obregón, P. Gonzállez-Hormanzábal, Int. J. Morphol. 2 (2003) 155.

[5] A. E. Ghaly, F. Alkoaik, A. Snow, Canadian Biosystems Engineering 49 (2007) 61.

[6] Hendig Winarno, Agustin N. M. Bagyo, Winarti A. Lindu, Ermin K. Winarno, Atom Indonesia 30(2) (2004) 35.

[7] US Food and Drug Administration, Pesticide Analytical Manual, Vol. I, FDA, Rockville, MD, 1979.

[8] P. Lopez-Roldan, M. J. Lopez de Alda, D. Barcelo, Anal. Bioanal. Chem. 378 (2004) 599.

[9] A. Pasha, Y. N. Vijayashankar, N. G. K. Karanth, J. AOAC Int. 79 (1996) 1009.

[10] A. Di Corcia, M. Marchetti, Anal. Chem. 63 (1991) 580.

[11] O. A. Zalat, M. A. Elsayed, M. S. Fayed, M. K. Abd El Megid, International Letters of Chemistry, Physics and Astronomy 2 (2014) 58-63.

[12] S. Magdic, A. Boyd-Boland, K. Jinno, J. B. Pawliszyn, J. Chromatogr. A 736 (1996) 219.

[13] P. L. Wylie, K. Uchiyama, J. AOAC Int. 79 (1996) 571.

[14] B. F. Scott, J. Struger, H. Tse, J. Environ. Anal. Chem. 61 (1995) 129.

[15] N. K. Wilson, J. C. Chuang, C. Lyu, J. Expo. Anal. Environ. Epidemiol. 11 (2001) 449.

[16] D. E. Glotfelty, M. S. Majewski, J. N. Seiber, Environ. Sci. Technol. 24 (1990) 353. 